\title{
Exopolissacarídeos de Cianobactérias ${ }^{1}$
}

\section{Cyanobacterial Exopolysaccharides}

\author{
Camilios Neto, Doumit²; Pinotti, Maria Helena P. ${ }^{3}$
}

\section{Resumo}

\begin{abstract}
Exopolissacarídeos são caracterizados como metabólitos secundários, produzidos principalmente durante a fase estacionária de crescimento do microorganismo. Desde o início da década de cinqüenta, a capacidade das cianobactérias de produzirem exopolissacarídeos (EPS) vem sendo relatada. Em condições de estresse, muitas cianobactérias produzem grande quantidade de EPS, e isso constitui uma estratégia metabólica desses microorganismos para crescimento e desenvolvimento em condições desfavoráveis. Os EPS têm, portanto, a função de proteger as cianobactérias de tensões de habitats extremos e outras condições prejudiciais. EPS são compostos cuja composição química é das mais variadas e complexas, apresentando estruturas e propriedades peculiares. Estes biopolímeros apresentam propriedades inibitórias contra alguns tipos de vírus e contra tumores. Apresentam também propriedades físico-químicas que trazem vantagens para uso industrial, podendo ser utilizados em indústrias de alimentos, têxteis e farmacêuticas. O uso biotecnológico pleno de EPS produzidos por cianobactérias ainda está por ser realizado. Este campo de pesquisa apresenta-se vasto, próspero e de grande potencial científico e lucrativo.
\end{abstract}

Palavras-chave: exopolissacarídeo, cianobactéria, polissacarídeo extracelular

\begin{abstract}
Exopolysaccharides (EPS) are characterized as secondary metabolites being produced predominantly during the stationary growth phase of the microorganism. The capacity of cyanobacteria to produce extracellular polysaccharides has been related since the beginning of the 1950s. In stress conditions, a lot of cyanobacteria produce a great amount of EPS, being in that way a metabolic strategy of these microorganisms for growth and development in unfavorable conditions. They have the purpose of protecting them against tensions of extreme habitats and harmful conditions. EPS are compounds whose chemical composition is complex and with peculiar properties. Those biopolimers present inhibition properties against several types of viruses as well as tumors. They also show physical-chemical properties with advantages for industrial use, being utilized in food, textiles, cosmetics and pharmaceutical industries. The full biotechnological use of EPS produced by cyanobacteria is expected soon. This research field is wide, prosperous and of great scientific and lucrative potential.

Key words: exopolysaccharide; cyanobacteria; extracellular polysaccharide.
\end{abstract}

1 Parte integrante da monografia apresentada ao Departamento de Bioquímica da Universidade Estadual de Londrina, em 2003, para obtenção do título de Especialização em Bioquímica Aplicada

2 Aluno do Curso de Especialização em Bioquímica Aplicada.

3 Docente do Departamento de Bioquímica - CCE - Universidade Estadual de Londrina. CP 6001, CEP 86051-990, Londrina, Paraná, Brasil.

* Autor para correspondência. 
O uso de exopolissacarídeos microbianos representa alternativa interessante aos polissacarídeos de plantas e de macroalgas que são tradicionalmente usados em indústrias de alimentos, têxteis, tintas, cosméticos, papel e farmacêutica, como estabilizadores, espessantes ou emulsificantes (DE PHILIPPIS; VINCENZINI, 1998; MORENO et al., 1998, 2000; OTERO; VINCENZINI, 2003). Muitos polissacarídeos microbianos são atualmente produtos da biotecnologia amplamente aceitáveis, enquanto outros estão ainda em fase de desenvolvimento (SUTHERLAND, 1998). Alguns apresentam propriedades químicas vantajosas para novas aplicações (MORENO et al., 1998). Analisando do ponto de vista de produção de biomassa, esses organismos apresentam taxas maiores de crescimento e são mais fáceis de manipular quanto às condições de produção de polissacarídeos do que plantas ou macroalgas (SUTHERLAND, 1998).

As cianobactérias, anteriormente denominadas algas azul - verdes, são organismos procariontes, apresentando a capacidade de realizar fotossíntese oxigênica, como as plantas, sendo autotróficas no seu modo dominante de nutrição (FAY, 1983). São caracterizadas por uma grande diversidade morfológica, podendo ser unicelulares ou filamentosas e encontradas na maior parte dos habitats aquáticos e terrestres, inclusive em ambientes inóspitos (DE PHILIPPIS; VINCENZINI, 1998; FAY, 1983). Neste texto, as cianobactérias serão alternativamente consideradas microalgas, como ainda o são na maior parte da literatura pertinente ao assunto.

Cianobactérias são uma fonte biológica bem conhecida de substâncias químicas de uso comercial, como ácidos orgânicos, proteínas, aminoácidos livres, carotenóides, ácidos graxos e ficobiliproteínas (PINOTTI; SEGATO, 1991; MORENO et al., 1998; YALCIN et al., 1994).

As cianobactérias são capazes de produzir polissacarídeos extracelulares (EPS). Desde o início da década de cinqüenta, essa capacidade vem sendo relatada. Esses polissacarídeos podem ser encontrados formando cápsulas que são estruturas compactas associadas com a superfície celular ou como massa mucilaginosa amorfa, fracamente ligada às células (FAY, 1983). Em muitos casos, podem ser liberados para o meio (DE PHILIPPIS; VINCENZINI, 1998).

Os exopolissacarídeos de cianobactérias são caracterizados por uma grande variedade tanto em número (2 a 10) como em tipo de monossacarídeos constitutivos (várias combinações de açúcares neutros ou ácidos). A maioria dos polímeros apresenta natureza aniônica, devido à presença de ácidos urônicos e/ou grupos carregados tais como piruvil ou sulfato. Adicionalmente, alguns podem também apresentar moléculas polipeptídicas e substituintes acetil, causando complexidade estrutural maior (DE PHILIPPIS; VINCENZINI, 1998).

Além de apresentarem propriedades físicoquímicas que trazem vantagens para sua utilização industrial na forma convencional, como gelificantes, emulsificantes, floculantes e hidratantes, a natureza aniônica dos EPS de cianobactérias os faz interessantes para aplicações biomédicas uma vez que tem sido demonstrado que os sulfatados podem ser inibidores de vários tipos de vírus e tumores (HAYAKAWA et al., 1997, 2000; HAYASHI; HAYASHI, 1996; HIRAHASHI et al., 2002; KAJI et al., 2002a, 2002b; LEE et al., 2000; MISHIMA et al., 1998), assim como para aplicações no campo da biorremediação para a remoção de metais tóxicos de águas poluídas (SINGH et al., 1999).

\section{Funções dos Exopolissacarídeos para as Cianobactérias}

É geralmente aceito que a produção desses polissacarídeos extracelulares representa uma estratégia metabólica para sobrevivência e crescimento das cianobactérias, especialmente sob condições ambientais desfavoráveis, como, por exemplo, em habitats extremos. Essa produção pode ter um papel protetor contra a dessecação,os agentes 
antibacterianos ou a predação por protozoários e, além disso, capacitar as cianobactérias a formar biofilmes em superfícies sólidas (DE PHILIPPIS; VINCENZINI, 1998; FAY, 1983). Registros de microfósseis sugerem que as cianobactérias estão presentes na Terra desde a era Arqueana há mais de 3,5 bilhões de anos (FAY, 1983; HELM et al., 2000). A capacidade de preservação das cianobactérias reflete a estabilidade intrínseca do seu polissacarídeo extracelular (EPS) e a habilidade deste de ligar-se a metais pesados assim como resistir à degradação (HELM et al., 2000). No entanto, existe uma grande falta de conhecimento sobre a função e relacionamento estrutura-função desses polímeros em cianobactérias (OTERO; VINCENZINI, 2003).

Muitos estudos têm abordado a capacidade de algumas cianobactérias produtoras de exopolissacarídeos de suportar o estresse da dessecação dos desertos ou em meios salinos (DE PHILIPPIS; VINCENZINI, 1998). Um dos gêneros bastante estudados é Nostoc $s p$, uma cianobactéria filamentosa que pode formar colônias microscópicas ou macroscópicas e é comum em ambientes terrestres e aquáticos. Este sucesso se deve em grande parte à sua habilidade de resistir à dessecação por meses ou anos e recobrar a atividade metabólica dentro de horas a dias após rehidratação (DODDS; GUDDER; MOLLENHAUER, 1995).

A produção de EPS por microorganismos confere a estes a capacidade de formar biofilmes em superfícies sólidas (DE PHILIPPIS; VINCENZINI, 1998), aumentando assim a capacidade de sua adaptação. Experimentos comprovaram a produção de um biofilme composto predominantemente por EPS de microalgas, que experimentam um estresse de transferência de condições de crescimento mixotróficas (crescimento em presença de luz e com suplementação de compostos orgânicos) para condições heterotróficas (metabolismo na ausência de luz) (SHIPIN et al., 1999).

A produção de EPS em excesso, por cianobactérias, em resposta a estresse causado por metais, mostra a capacidade das microalgas de criar estratégias que garantam sua sobrevivência. Esses biopolímeros, devido a sua natureza aniônica, apresentam uma grande capacidade de interagir fortemente com cátions, tendo um papel importante no seqüestro ou imobilização de íons metálicos, que são essenciais ou perigosos para as cianobactérias (DE PHILIPPIS; VINCENZINI, 1998). Singh et al. (1999) relataram estímulo de biossíntese de exopolissacarídeo em Nostoc spongiaeforme pelos cátions $\mathrm{Cu}, \mathrm{Ni}$ ou $\mathrm{Hg}$.

Dodds, Gudder e Mollenhauer (1995), em uma revisão da ecologia do gênero Nostoc, comentam que a densa camada de mucilagem que cerca os tricomas pode tornar essas microalgas alimentos menos preferidos a predadores em comparação a microalgas destituídas de cápsula mucilaginosa.

A microalga Phormidium J-1 sintetiza um heteropolissacarídeo chamado emulciana, o qual contém ácidos graxos e proteínas na sua composição. Essa composição lhe confere vários graus de hidrofobicidade, de que decorre a sua capacidade de floculação. O metabolismo energético das microalgas depende da disponibilidade de luz e é proposto que o papel de floculação de partículas do emulciana leva a uma sedimentação de partículas de argila suspensas. Desse fato advém o clareamento da coluna de água, e dele resulta o incremento na disponibilidade de luz (DE PHILIPPIS; VINCENZINI, 1998).

Outro papel que os polissacarídeos de cianobactérias desempenham é na proteção da nitrogenase, com relação aos efeitos nocivos do oxigênio. Em Nostoc cordubensis, parece ser essencial a presença do envelope mucilaginoso para a proteção da atividade de nitrogenase contra a inativação promovida pelo oxigênio atmosférico (PROSPERI, 1994). Já em Cyanothece BH68, além dos exopolissacarideos atuarem como uma barreira física ao oxigênio, poderiam também servir como quelantes de ferro e cálcio, essenciais para a fixação do nitrogênio (REDDY et al., 1996).

Em algumas cianobactérias simbiônticas com plantas superiores, o EPS pode atuar como adesivo para as células. Assim, o EPS da simbionte Anabaena azollae é considerado essencial para fixação desta cianobactéria na planta anfitriã Azolla filiculoides 
(ROBINS et al., 1986) e os exopolissacarídeos de uma cepa de Nostoc sp são responsáveis pela firme associação dos filamentos às raízes do trigo. No entanto, verifica-se que uma cepa de Anabaena não foi capaz de se ligar, mesmo apresentando exopolissacarídeo (GANTAR et al., 1995).

Dessa forma, os exopolissacarídeos de microalgas podem ter uma variedade de funções diferentes dependendo da cepa, das características físicoquímicas e do seu habitat natural.

\section{Aplicações dos Exopolissacarídeos}

Na Tabela 1, pode-se observar as patentes de exopolissacarídeos de cianobactérias registradas no período de 1988 a 1998 e suas respectivas aplicações, sendo um número baixo devido à falta de informações sobre os aspectos tecnológicos, econômicos e de aplicações desses polímeros (DE PHILIPPIS; VINCENZINI, 1998).

Tabela 1 - Patentes de exopolissacarídeos produzidos por cianobactérias no período de 1989 a 1998.

\begin{tabular}{|c|c|c|c|c|}
\hline Ano & $\begin{array}{c}\mathrm{N}^{\circ} \text { da } \\
\text { Patente }\end{array}$ & País & Título & $\begin{array}{c}\text { Cianobactéria } \\
\text { produtora }\end{array}$ \\
\hline 1989 & 4.826 .624 & EUA & $\begin{array}{l}\text { Bioemulsificante } \\
\text { para dispersão de } \\
\text { hidrocarboneto(s) } \\
\text { líquido(s) em um } \\
\text { segundo líquido. }\end{array}$ & Phormidium spp. \\
\hline 1990 & 4.894 .161 & EUA & $\begin{array}{l}\text { Clarificação de } \\
\text { líquidos que } \\
\text { contém partículas } \\
\text { com biofloculante. }\end{array}$ & Phormidium spp. \\
\hline 1992 & 4.370 .098 & Japão & $\begin{array}{l}\text { Produção contínua } \\
\text { de polissacarídeos } \\
\text { usados como } \\
\text { substituintes de } \\
\text { Agar-agar, etc. }\end{array}$ & Spirulina platensis \\
\hline 1993 & 5.049 .491 & Japão & $\begin{array}{l}\text { Produção de } \\
\text { polissacarídeo de } \\
\text { alto rendimento. }\end{array}$ & $\begin{array}{l}\text { Aphanocapsa } \\
\text { halophytica }\end{array}$ \\
\hline 1993 & 5.250 .201 & EUA & $\begin{array}{l}\text { Recuperação } \\
\text { secundária de } \\
\text { petróleo de } \\
\text { formações } \\
\text { subterrâneas. }\end{array}$ & Phormidium spp. \\
\hline 1994 & 6.040 .880 & Japão & $\begin{array}{l}\text { Material cosmético } \\
\text { com suficiente } \\
\text { efeito para clarear a } \\
\text { pele e com alta } \\
\text { estabilidade e } \\
\text { segurança. }\end{array}$ & Aphanocapsa spp. \\
\hline
\end{tabular}

Fonte: De Philipps e Vincenzini (1998)
Por muitos anos, acreditou-se que só as células eucarióticas eram capazes de produzir polissacarídeos sulfatados, uma vez que a sulfatação do polímero ocorre no complexo de Golgi (DE PHILIPPIS; VINCENZINI, 1998).

Nos últimos 10 anos, essa afirmativa vem se tornando falsa, considerando o número crescente de cianobactérias produtoras de EPS isoladas de águas doces e salgadas e de ambientes hiper-salinos, e que apresentam grupos sulfato como constituintes dos seus polissacarídeos (DE PHILIPPIS; VINCENZINI, 1998).

Muita atenção tem sido dada a esses polissacarídeos sulfatados tendo em vista seu potencial para aplicações biomédicas. Assim, atribuem-se atividades biológicas a esses polissacarídeos que apresentam grupos sulfato, uma vez que esses apresentam propriedades inibitórias contra vários tipos de vírus e tumores (DE PHILIPPIS; VINCENZINI, 1998).

Os exopolissacarídeos produzidos por microalgas podem ser retirados por extração com água quente (YALCIN et al., 1994). A espirulana cálcica é um exopolissacarídeo ácido, sulfatado, isolado e extraído com água quente da microalga Spirulina por Hayashi et al. (HAYAKAWA et al., 1997). Extratos de Spirulina têm sido administrados por via oral como agentes anti-tumorais e antivirais atuando no sistema imunológico por mecanismos moleculares não totalmente definidos (HIRAHASHI et al., 2001). A espirulana cálcica tem apresentado uma potente atividade contra os vírus herpes simplex tipo 1 e da imunodeficiência humana tipo 1 (LEE et al., 2000). Também atua contra o citomegalovírus humano, vírus do sarampo, vírus da caxumba, vírus da gripe tipo A e HIV-1, promovendo uma inibição seletiva da penetração do vírus nas células do hospedeiro (HAYASHI; HAYASHI, 1996).

Hirahashi et al. (2002), em um estudo sobre a ativação do sistema imune inato por administração oral de extrato de Spirulina platensis, verificaram aumento de produção de interferon e aumento da citotoxidade das células NK. 
Em relação a aspectos da regulação celular como fibrinólise, remodelamento de tecidos, inflamação e metástase tumoral, acredita-se que a conversão da pro-enzima plasminogênio em plasmina ocupe um papel importante. A plasmina é a forma ativa da enzima e a sua conversão é catalisada por uma serina protease, t-PA (ativador de plasminogênio tipo tecidual). Hayakawa et al. (1997) estudaram a ativação da síntese de t-PA pela espirulana cálcica, em fibroblastos de pulmão fetal humano (células IMR-90). A espirulana cálcica estimulou a síntese de t-PA em células IMR-90, influenciando processos pós-transcricionais. A remoção do cálcio da espirulana cálcica resultou em uma perda significativa do efeito estimulatório.

A inibição da invasão tumoral e a redução de metástase pela espirulana cálcica estão relacionadas com a inibição da invasão do tumor através de membrana basal reconstituída, o que, provavelmente, previne a adesão e migração das células tumorais para o substrato de laminina e também com a inibição da atividade da heparanase (MISHIMA et al., 1998). Assim, o que pode ser visto são os efeitos combinados da utilização desse EPS como inibidor de neoplasias.

O íon cálcio da espirulana cálcica foi trocado por vários cátions metálicos e esta foi testada com relação a seus efeitos inibitórios sobre a replicação do vírus do herpes simples tipo 1. A troca do íon cálcio por sódio e potássio manteve a atividade antiviral, enquanto cátions divalentes e trivalentes reduziram a atividade antiviral. A despolimerização da espirulana cálcica com peróxido de hidrogênio promoveu o decréscimo da atividade antiviral, conforme o peso molecular diminuía (LEE et al., 2001).

A espirulana cálcica pode retardar o processo de reparo de danificações do endotélio vascular por inibição da proliferação das células endoteliais, por meio da diminuição da habilidade de resposta à estímulo por excesso de fator de crescimento endógeno do fibroblasto (FGF-2) (KAJI et al., 2002a ).
A espirulana sódica preparada com a troca do íon cálcio por sódio, em experimento de proliferação de culturas de células de endotélio vascular, também mostrou ser inibidora da proliferação dessas células. Já que o reparo do endotélio modificado é um dos mais importantes eventos para a prevenção da aterosclerose, os efeitos inibitórios da espirulana cálcica e da espirulana sódica podem ser inapropriados para um medicamento anti-aterogênico (KAJI et al., 2002b).

Brüll et al. (2000) estudaram a ação do EPS isolado de Nostoc commune coletado no campo, no sistema de complemento, e verificaram que este tinha um forte efeito neste sistema, como foi mostrado por testes de fixação de complemento.

A hiperprodução de EPS por cianobactérias em resposta ao estresse causado por metais mostra a capacidade de as microalgas criarem estratégias que garantam sua sobrevivência, uma vez que esses polímeros têm capacidade de se ligar fortemente a cátions (SINGH et al., 1999). Assim, esse aspecto deve ser levado em consideração para o seu uso em processos de biorremediação em áreas contaminadas por metais (SINGH et al., 1999).

Cianobactérias como a Nostoc muscorum e Tolypothrix tenuis são capazes de produzir enzimas extracelulares que decompõem resíduos orgânicos (DE CAIRE et al., 2000). Elas também são usadas como inoculantes em solos para aumentar o conteúdo de polissacarídeos e a atividade microbiana dos mesmos (DE CAIRE et al., 2000). Tanto a biomassa dessas cianobactérias quanto seus EPS, quando inoculados no solo, aumentaram a atividade de várias enzimas extracelulares presentes neste. Dessa forma, o que se tem é a utilização de EPS como inoculante para solo com o objetivo de aumentar a atividade de exoenzimas. Estas, por sua vez, têm como finalidade decompor resíduos orgânicos, o que provoca um aumento final da fertilidade (DE CAIRE et al., 2000).

Exopolissacarídeos microbianos têm valor comercial significativo com respeito à produção de géis e modificação de propriedades reológicas de 
sistemas aquosos. Moreno et al. (2000), estudaram o exopolissacarídeo produzido pela cianobactéria Anabaena sp quanto às suas características químicas e reológicas, em cultura em batelada diazotrófica. Verificaram que esse exopolissacarídeo atua como um bom estabilizador de dispersão e como agente emulsificante, características que foram comprovadas pelo espectro de viscoelasticidade do referido EPS.

\section{Propriedades Reológicas e Químicas dos Exopolissacarídeos de Cianobactérias}

De Philippis e Vincenzini (1998) relataram que, até 1998,70 cepas haviam sido estudadas com relação à produção de EPS sendo a maior parte dos estudos referentes à determinação da composição em açúcares dos polímeros. Os açúcares encontrados em EPS de cianobactérias, no geral, são as hexoses, glucose, galactose e manose; as pentoses, ribose, xilose e arabinose; as desoxihexoses, fucose e ramnose e os açúcares ácidos,ácido glicurônico e galacturônico. O açúcar mais freqüentemente encontrado é a glucose, em mais de $90 \%$ dos EPS, seguido por galactose, manose e ramnose (80-85\% dos EPS). Glucose é também o mais abundante, mas há polímeros que apresentam outros açúcares com maior concentração, como arabinose, galactose ou fucose .

A maior parte dos polissacarídeos de cianobactérias apresentam natureza aniônica, muitos contendo dois diferentes ácidos urônicos, o que é raro em outros grupos microbianos. Freqüentemente possuem um ou dois tipos de pentoses, açúcares que normalmente estão ausentes em outros polissacarídeos de procariontes. A maioria dos EPS de cianobactérias é relativamente complexa, sendo esses polissacarídeos compostos de seis ou mais tipos de monossacarideos, uma característica que também não é apresentada por EPS de outros microorganismos ou macroalgas (DE PHILIPPIS; VINCENZINI, 1998).

A cianobactéria Cyanospira capsulata foi isolada do lago Magadi, Kênia, em 1982, por Florenzano et al. (MARRA et al., 1990). Esta produz um exopolissacarídeo cuja composição química, estrutura e características reológicas vêm sendo estudadas (CESÁRIO et al., 1990; GAROZZO et al., 1995, 1998; MARRA et al., 1990). O EPS produzido por esta cianobactéria apresenta uma composição em monossacarídeos estável durante as diversas fases e condições de crescimento. A composição do EPS sintetizado é a mesma após mais de 10 anos de cultivo. Também a capacidade de sintetizar a sua cápsula e liberá-la tem sido mantida através dos anos por essa cianobacteria (DE PHILIPPIS; VINCENZINI, 1998). Garozzo et al. (1998) propuseram para esse EPS, um octassacarideo como unidade repetidora, apresentando os seguintes carboidratos: fucose, arabinose, glucose, manose, $\mathrm{N}$ acetilglucosamina, acetilgalactose e o açúcar raro 4o-(1 carboxietil) manose.

Lee et al. (1998) relataram a purificação do exopolissacarídeo espirulana cálcica, obtida por cromatografia em coluna de Sepharose 6B, DEAEToyopearl 650M, e Toyopearl HW-65(S),. A análise estrutural revelou os seguintes açúcares na sua composição: ramnose, 3-O-metilramnose (acofriose), 2,3-di-O-metilramnose, 3-O-metilxilose, ácidos urônicos e sulfato. A cadeia principal é formada por ramnoses ligadas por ligação glicosídica tipo 1,3 e unidades de 3-O-metilramnose ligadas por ligação 1,2 com algumas substituições de sulfato na posição 4. Também foram detectados resíduos de 2,3di-O-metilramnose e 3-O-metilxilose não redutores que compõem a porção final do polímero. O peso molecular aparente obtido foi de 7,46X $10^{4} \mathrm{Da}$.

Lee et al. (2000), em um estudo posterior, com análises estruturais detalhadas da espirulana cálcica por ESI-MS ("Eletrospray Ionization Mass Spectrometry"), propuseram que o EPS espirulana cálcica é composto por duas unidades de dissacarídeos que se repetem, O-ramnosil-acofriose e O-hexuronosil-ramnose (ácido aldobiurônico).

Nicolaus et al. (1999), estudando a produção e composição química de EPS de cianobactérias 
heterocísticas e não heterocísticas de várias fontes, realizaram a extração do EPS da cápsula (CPS) e o liberado para o meio de cultivo (RPS). Em geral, RPS foi mais abundante que CPS. Phormidium sp. foi o melhor produtor de EPS. Entre as cianobactérias com heterocistos pertencentes ao grupo das Nostocaceae, as melhores produtoras foram Anabaena WSAP e Anabaena torulosa. Nos outros grupos com heterocistos, Chlorogloeopsis sp. 6912 produziu mais EPS. Geralmente glucose e galactose estavam presentes em maior quantidade nas espécies examinadas, com exceção de algumas espécies que apresentaram manose e xilose em maior quantidade. Aminoaçúcares e ácidos urônicos foram também encontrados.

O polissacarídeo capsular produzido pela cianobactéria termofílica Mastigocladus laminosus foi isolado e representou uma significante proporção de $20 \%$ do total de biomassa. O polissacarídeo isolado após a precipitação com brometo de hexadeciltrimetilamônia e degradação enzimática mostrou ser homogêneo através de cromatografia em gel. Nas análises do polissacarídeo por cromatografia gasosa-liquida dos glicosídeos trimetilsilados (S)(+)-2-butil, pôde-se observar a presença de Lramnose, L-fucose, D-xilose, D-manose, D-glicose, D-galactose, D-ácido galacturônico e D-ácido glicurônico. O polímero purificado continha $2 \%$ (W/ W) de proteína, enquanto que o conteúdo de proteína do polissacarídeo capsular antes da purificação foi 24\% (W/W) (GLOAGUEN et al., 1999).

O exopolissacarídeo purificado produzido pela cianobactéria Anabaena sp. ATCC 3304, apresentou um conteúdo total de carboidrato de $72,3 \%$ do peso seco do EPS. O polissacarídeo também continha um material polipeptídico, que corresponde a aproximadamente $7 \%$ do peso seco do EPS. A cromatografia em papel da fração de açúcar neutro isolado da hidrólise do EPS revelou a presença de xilose, galactose, glucose e manose. $\mathrm{Na}$ cromatografia gasosa-líquida de derivados dos alditóis-acetato dos açúcares neutros, a galactose e a glicose estão presentes em proporções eqüimoleculares, com a xilose em maior proporção e a manose em menor quantidade. A razão molar encontrada foi de 11:5:5:1 para xilose, galactose, glucose, e manose respectivamente.Na fração ácida da hidrólise do EPS analisada encontrou-se um conteúdo de ácido urônico de 19,4\% do peso seco do EPS (MORENO et al., 2000).

A estrutura do polissacarídeo viscoso extracelular de Nostoc commune DRH-1, tolerante à dessecação, foi determinada através de métodos espectroscópicos e cromatográficos. O polissacarideo tem uma estrutura não usual, uma vez que possui uma cadeia principal de xilogalactoglucana ligada 1-4 com Dribofuranose e 3-O-\{(R)-1 carboxietil $\}$ ácido glucurônico (ácido nosturônico) pendentes. A presença de O-ribose e ácido nosturônico como grupos periféricos é também incomum. $\mathrm{O}$ ácido nosturônico estava presente nas glucanas de $N$. Commune de diversas localizações geográficas, sugerindo que é um componente integral deste anidrófilo cosmopolita (HELM et al., 2000).

Brüll et al. (2000) caracterizaram a estrutura de EPS de Nostoc commune HB261 cultivado em laboratório e amostras coletadas no campo, sendo que as principais diferenças entre os dois grupos foram a presença de quantidades substanciais de arabinose, 2-O-metilglucose e ácido glucurônico no último.

Morris et al. (2001), ao estudarem as propriedades hidrodinâmicas do EPS da cianobactéria halofítica Aphanothece halophytica GRO2 em comparação com xantana, verificaram que o exopolissacarídeo é semelhante à xantana em suas propriedades físicas, pelo menos no sistema estudado.

\section{Condições de Cultivo}

Estudos de fatores que estimulam a produção de exopolissacarídeos no sentido de se obter meios e condições de cultivo otimizadas para produção deste polímero por cianobactérias produtoras de EPS, ainda mostram-se escassos. A maioria dos estudos 
encontrados em relação a esses fatores dizem respeito à avaliação da deficiência de nitrogênio utilizada como estímulo para produção de exopolissacarídeo por esses microorganismos (DE PHILLIPIS; VINCENZINI, 1998).

A produção de exopolissacarídeo pela cianobactéria Anabaena sp. ATCC 33047 pode ser aumentada pela deficiência de nitrogênio e níveis reduzidos de atividade de nitrogenase (MORENO et al., 1998).

Nicolaus et al. (1999) descreveram a influência de alguns fatores físicos e nutricionais sobre a produção de exopolissacarídeos de cianobactérias heterocísticas e não heterocísticas. Phormidium sp. apresentou maior produção de EPS em condição de crescimento padrão (meio de cultura BG11, aeração e iluminação contínua). Houve uma notável diminuição da produção de EPS com a introdução de ciclos com ausência de luz (12h com luz e $12 \mathrm{~h}$ no escuro), ausência de aeração e ausência de fosfato. $\mathrm{O}$ aumento da quantidade de fosfato, $\mathrm{o}$ aumento da quantidade de nitrogênio e a ausência de nitrogênio combinado foram fatores que também levaram a uma diminuição da produção de EPS em relação às condições de crescimento padrão. Os resultados obtidos com a cianobactéria Phormidium sp. indicaram que as condições de crescimento desfavoráveis induzidas por fatores nutricionais e físicos interferiram significativamente na produção de EPS desse microrganismo (NICOLAUS et al., 1999).

A Spirulina sp. apresentou quantidade total de biossíntese de exopolissacarídeo semelhante em condição de crescimento padrão em relação ao aumento de nitrogênio em $4 \mathrm{~g} / \mathrm{L}$ e também em relação ao aumento de fosfato. Já a ausência de $\mathrm{NaCl}$ e aumento da temperatura causou uma pequena diminuição na produção de EPS. Quando o conteúdo de nitrogênio foi diminuído ou estava ausente houve um forte aumento na quantidade total de polissacarídeo. Um efeito semelhante foi observado na ausência de fosfato. No caso da Spirulina sp. a síntese de EPS foi maior através da limitação de nitrogênio e, menor, pela limitação de fósforo. Em contraste, a deficiência de $\mathrm{NaCl}$ não induziu uma mudança significativa na síntese de EPS (NICOLAUS et al., 1999).

As duas espécies de Anabaena (Anabaena torulosa e Anabaena sp. WSAF) apresentaram maior produção de EPS em condição de crescimento padrão (meio de cultura BG11, aeração e iluminação contínua). Houve alteração da quantidade de EPS total produzido, devido a mudanças dos parâmetros físicos e químicos. A ausência, ou o aumento da concentração de nitrogênio, causou nas duas espécies a diminuição na produção de EPS. O aumento de fosfato no meio de cultivo teve pequena influência na produção de EPS em ambas espécies, enquanto sua ausência deu lugar a uma redução de 90\% na produção de EPS na espécie Anabaena sp. WSAF. A introdução de ciclos com ausência de luz (12h com luz e $12 \mathrm{~h}$ no escuro) e a ausência de aeração causou uma diminuição drástica no rendimento do EPS (NICOLAUS et al., 1999).

\section{Conclusão}

Desde o início dos anos cinqüenta, a capacidade das cianobactérias de produzir polissacarídeos extracelulares (EPS) vem sendo relatada. Os exopolissacarídeos caracterizam-se como metabólitos secundários, sendo produzidos, predominantemente, na fase de crescimento estacionária do microrganismo. São compostos cuja composição química caracteriza-se pela presença de inúmeras moléculas complexas com estruturas e propriedades particulares. Devido a suas propriedades físico-químicas e reológicas estes EPS apresentam vantagens para uso industrial, podendo ser empregados nas industrias de alimentos, têxtil, cosméticos e farmacêutica.

Nos últimos 10 anos, um número crescente de cianobactérias produtoras de EPS foi isolado de águas doces e salgadas e de ambientes hiper-salinos. Muitos destes EPS apresentam grupos sulfato como constituintes. 
Muita atenção tem sido dada a esses polissacarídeos sulfatados, tendo em vista seu provável valor para aplicações biomédicas, uma vez que esses biopolímeros apresentam propriedades inibitórias contra vários tipos de vírus e tumores.

Dessa forma, nos ultimos anos, mais atenção tem sido dada à produção de EPS por cianobactérias, no intuito de se produzir EPS em larga escala, para utilização industrial. Todavia, existe ainda uma grande deficiência no que se diz respeito ao conhecimento acerca desses polissacarídeos extracelulares produzidos por cianobactérias, sendo que os estudos ainda são escassos e deixam lacunas a serem preenchidas. Desse modo, faz-se necessário um aprofundamento no conhecimento sobre esses biopolímeros ao nível de caracterização estrutural, sendo relevante a análise das suas estruturas tanto para o maior entendimento das suas propriedades reológicas e físico-químicas, como para fornecer informações de antigenicidade e fisiologia microbiana. São necessários também estudos que enfatizem os fatores que estimulam a produção de exopolissacarídeos, no sentido de se obter meios e condições de cultivo otimizadas para a produção destes polímeros por cianobactérias produtoras de EPS, uma vez que estes ainda são escassos. Assim, poderemos atingir um nível pleno de utilização biotecnológica dos mesmos. Portanto, este se apresenta como um campo vasto, próspero e com grande potencial de aplicação e obtenção de resultados de ampla significância do ponto de vista científico, além de promissora lucratividade.

\section{Agradecimentos}

Agradecimentos à Professora Mara Lúcia L. Ribeiro pela correção e revisão crítica.

\section{Referências}

BRÜLL, L. P. et al. Studies of polysaccharides from three edible species of Nostoc (Cyanobacteria) with different colony morphologies: structural characterization and effect on the complement system of polysaccharides from Nostoc commune. Journal of Phycology, Lawrence, v.36, p.871-881, 2000.

CESÁRIO, A. et al. Physicochemical properties of the exocellular polysaccharide from Cyanospira capsulata. International Journal of Biological Macromolecules, Oxford, v.12, p.79-84, 1990.
DE CAIRE, G. Z. et al. Changes in soil enzyme activities following additions of cyanobacterial biomass and exopolysaccharide. Soil Biology \& Biochemistry, Elmsford, v.32, p.985-1987, 2000.

DE PHILIPPIS, R.; VINCENZINI, M. Exocellular polysaccharides from cyanobacteria and their possible applications. FEMS Microbiology Reviews, Amsterdam, v.22, p.151-175, 1998.

DODDS, W. K.; GUDDER, D. A.; MOLLENHAUER, D. The ecology of Nostoc. Journal of Phycology, Lawrence, v.31, p.2-18, 1995.

ETESHOLA, E.; GOTTLIEB, M.; ARAD, S. M. Dilute solution viscosity of red microalga exopolysaccharide. Chemical Engineering Science, Great Britain, v.51, n.9, p.1487-1494, 1996.

FÁBREGAS, J. et al. Mixotrophic production of phycoerythrin and exopolysaccharide by the Porphyridium cruentum. Cryptogamie, Algology, Paris, v.20, n.2, p.89-94, 1999.

FÁBREGAS, J. et al. Renewal rate of semicontinuous cultures of the microalga Porphyridium cruentum modifies phycoerythrin, exopolysaccharide and fatty acid productivity. Journal of Fermentation and Bioengineering, Osaka, v.86, p.477-481, 1998.

FAY, P. The Blue Greens. London: Edward Arnold, 1983.

GANTAR, M. et al. Role of extracellular polysaccharide in the colonization of wheat (Tritium vulgare L.) roots by $\mathrm{N}^{2}$ - fixing cyanobacteria. Biology and Fertility of Soils, Berlin, v.19, p.41-48, 1995.

GAROZZO, D. et al. Identification of $\mathrm{N}$-acetylglucosamine and 4-O-[1-carboxyethyl] mannose in the exopolysaccharide from Cyanospira capsulata. Carbohydrate Research, Amsterdam, v.270, p.97-106, 1995.

GAROZZO, D. et al. The structure of the exocellular polysaccharide from the cyanobacterium Cyanospira capsulata. Carbohydrate Research, Amsterdam, v.307, p.113-124, 1998.

GERESH, S.; MAMONTOV, A.; WEISTEIN, J. Sulfation of extracellular polysaccharides of red microalga: preparation, characterization and properties. Journal of Biochemical and Biophysical Methods, Amsterdam, v.50, p.179-187, 2002.

GLOAGUEN, V. et al. Capsular polysaccharide produced by the termophilic cyanobacterium Mastigocladus laminosus. European Journal of Biochemistry, Belfast, v.266, p.762-770, 1999.

HAYAKAWA, Y. et al. Calcium spirulan as an inducer of tissue-type plasminogen activator in human fetal lung fibroblasts. Biochimica et Biophysica Acta, Amsterdam, v.1355, p.241-247, 1997.

HAYAKAWA, Y. et al. Inhibition of thrombin by sulfated polysaccharides isolated from green algae. Biochimica et Biophysica Acta, Amsterdam, v.1543, p.86-94, 2000. 
HAYASHI, T.; HAYASHI, K. Calcium spirulan, an inhibitor of enveloped virus replication, from a blue-green alga Spirulina platensis. Journal of Natural Products, Columbus, v.59, p.83-87, 1996.

HELM, R. F. et al. Structural Characterization of the Released Polysaccharide of Desiccation-Tolerance Nostoc commune DRH-1. Journal of Bacteriology, Washington, v.182, p.974-982, 2000.

HIRAHASHI, T. et al. Activation of the human innate immune system by Spirulina: augmentation of hot water extract of Spirulina platensis. International Immunopharmacology, Amsterdam, v.2, p.423-434, 2002.

HUHEIHEL, M. et al. Activity of Porphyridium sp. polysaccharide against herpes simplex viruses in vitro and in vivo. Journal of Biochemical and Biophysical Methods, Amsterdam, v.50, p.189-200, 2002.

KAJI, T. et al. Repair of wounded monolayers of cultured bovine aortic endothelial cells is inhibited by calcium spirulan, a novel sulfated polysaccharide isolated from Spirulina platensis. Life Sciences, Elmsford, v.70, p.1841$1848,2002 \mathrm{a}$.

KAJI, T. et al. Inhibition of cultured bovine aortic endothelial cell proliferation by sodium spirulan, a new sulfated polysaccharide isolated from Spirulina platensis. Planta Medica, New York, v.68, p.505-509, 2002b.

LEE, J. B. et al. Further Purification and Structural Analysis of Calcium Spirulan from Spirulina platensis. Journal of Natural Products, Columbus, v.61, p.11011104, 1998.

LEE, J. B. et al. Structural Analysis of Calcium Spirulan (Ca-SP)-Derived Oligosaccharides Using Eletrospray Ionization Mass Spectrometry. Journal of Natural Products, Columbus, v.63, p.136-138, 2000.

LEE, J. B. et al. Effects of Structural Modification of Calcium Spirulan, a Sulfated Polysaccharide from Spirulina Platensis, on Antiviral Activity. Chemical Pharmaceutical Bulletin, Tokyo, v.49, n.1, p.108-110, 2001.

MARRA. M. et al. Structural characterization of the exocellular polysaccharide from Cyanospira capsulata. Carbohydrate Research, Amsterdam, v.197, p.338-344, 1990.

MISHIMA, T. et al. Inhibition of tumor invasion and metastasis by calcium spirulan ( $\mathrm{Ca}-\mathrm{SP}$ ), a novel sulfated polysaccharide derived from a blue-green alga, Spirulina platensis. Clinical \& Experimental Metastasis, Oxford, v.16, p.541-550, 1998.

MORENO, J. et al. Exopolysaccharide production by the cyanobacterium Anabaena sp. ATCC 33047 in batch and continuous culture. Journal of Biotechnology, Amsterdam, v.60, p.175-182, 1998.

MORENO, J. et al. Chemical and Rheological Properties of an Extracellular Polysaccharide Produced by the Cyanobacterium Anabaena sp. ATCC 33047. Biotechnology \& Bioengineering, New York, v.67, p.283-290, 2000.
MORRIS, G. A. et al. Hydrodynamic characterisation of the exopolysaccharide from the halophilic cyanobacterium Aphanothece halophytica GR02: a comparison with xanthan. Carbohydrate Polymers, Barking, v.44, p.261-268, 2001.

NICOLAUS, B. et al. Chemical composition and production of exopolysaccharides from representative members of heterocystous and non-heterocystous cyanobacteria. Phytochemistry, New York, v.52, p.639647, 1999.

OTERO, A.;VINCENZINI, M. Extracellular polysaccharide synthesis by Nostoc strains as affected by N source and light intensity. Journal of Biotechnology, Amsterdam, v.102, p.143-153, 2003.

PINOTTI, M. H. P.; SEGATTO, R. Cianobactérias: importância econômica. Semina, Londrina, v.12, n.4, p.275-280, 1991.

PROSPERI, C. H. A cyanophyte capable of fixing nitrogen under high levels of oxygen. Journal of Phycology, Lawrence, v.30, p.222-224, 1994.

REDDY, K. J. et al. Phenotypic variation in exopolysaccharide production in the marine, aerobic nitrogen-fixing unicellular cianobacterium. World Journal of Microbiology \& Biotechnology, Oxford, v.12, p.311318, 1996.

ROBINS, R. J. et al. Mucilage acts to adhere cyanobacteria and cultured plant cells to biological and inert surfaces. FEMS Microbiology Letters, Amsterdam, v.34, p.155-160, 1986.

SHIPIN, O. V.; ROSE, P. D.; MEIRING, P. G. J. Microbial processes underlying the PETRO concept (trickling filter variant). Water Research, New York, v.33, n.7, p.1645$1651,1999$.

SHIPIN, O. V et al. Integrating ponds and activated sludge process in the PETRO concept. Water Research, New York, v.33, n.8, p.1767-1774, 1999.

SINGH, N. et al. Thiol and exopolysaccharide production in a cyanobacterium under heavy metal stress. Process Biochemistry, London, v.35, p.63-68, 1999.

SOGAWA, K. et al. Induction of apoptosis and inhibition of DNA topoisomerase-1 IN K-562 cells by a marine microalgal polysaccharide. Life Sciences, Elmsford, v.66, n.16, p.227-231, 2000.

SUTHERLAND, I. W. Novel and established applications of microbial polysaccharides. Trends in Biothecnology, Amsterdam, v.16, p.41-46, 1998.

VONSHAK, A. Recent Advances in microbial biotechnology. Biotechnology Advances, New York, v.8, p.709-727, 1990.

YALCIN, I. et al. Characterization of the extracellular polysaccharide from freshwater microalga Chlorella sp. Lebensmittel Wissenschaft. und Technology, London, v.27, p.158-165, 1994. 